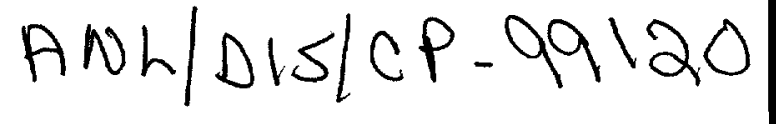

\title{
VALUE OF THE INTERNET IN EMERGENCY RESPONSE
}

Donald E. Newsom, Caroline L. Herzenberg, and Craig E. Swietlik

Decision and Information Sciences Division

Argonne National Laboratory

Argonne, IL 60439

\section{ABSTRACT}

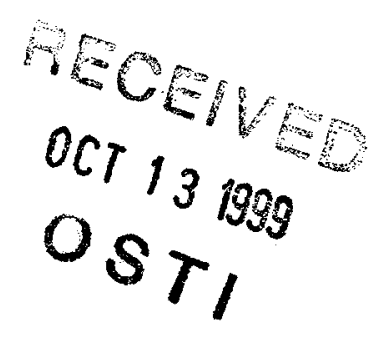

Can the Internet be of value in emergency response? The answer is yes, judging by its use in the Kobe earthquake in Japan in 1995, ice storms in the United States and Canada in 1998, and other disasters. Current and future areas of application are numerous, including exchanging messages, documents, and data files via e-mail; accessing operational data on-line; visualizing events via photos and maps; providing backup communications in lieu of broadcast media; exchanging information between crisis managers and responders; and providing information to media and the public. However, the Internet has some drawbacks, such as hardware/software requirements, computer literacy requirements, traffic jams, dependence on power and communication networks, and risks to information integrity and security. This paper examines some of the advantages, drawbacks, concerns, and potential uses of the Internet for emergency response.

\section{INTRODUCTION}

The Internet is a valuable component of emergency preparedness. The Internet has been used in networking on a daily basis by e-mail and in making available resources to the emergency preparedness community. In some states, networks connect local governments with state emergency operations centers. The amount of information on emergency preparedness on the Internet is growing rapidly. Uses of the Internet in crisis situations have grown less rapidly. Experience with the Internet in disaster operations is even more limited. Much more can be done to use the Internet in coping with disasters. As access to the Internet increases, the uses of the Internet in dealing with emergencies are expected to flourish. This paper examines some uses of the Internet in disasters and addresses advantages, drawbacks, concerns, and potential uses of the Internet for emergency response.

\section{EXAMPLES OF INTERNET USE IN DISASTERS}

The Internet has been used before, during, and after several disasters. It has proved useful when other communication systems have failed and as a supplementary form of communication.

Kobe Earthquake, Japan, 1995

The 1995 Kobe earthquake is prominent among the disasters in which the Internet was used. It was used initially to provide news about the earthquake. Soon a web site was established (SONY Computer Science Laboratories, 1995) to provide public information such as government announcements, damage information, including maps and images, information on relief efforts, 


\section{DISCLAIMER}

This report was prepared as an account of work sponsored by an agency of the United States Government. Neither the United States Government nor any agency thereof, nor any of their employees, make any warranty, express or implied, or assumes any legal liability or responsibility for the accuracy, completeness, or usefulness of any information, apparatus, product, or process disclosed, or represents that its use would not infringe privately owned rights. Reference herein to any specific commercial product, process, or service by trade name, trademark, manufacturer, or otherwise does not necessarily constitute or imply its endorsement, recommendation, or favoring by the United States Government or any agency thereof. The views and opinions of authors expressed herein do not necessarily state or reflect those of the United States Government or any agency thereof. 


\section{DISCLAIMER}

Portions of this document may be illegible in electronic image products. Images are produced from the best available original document. 
status of critical public services, lists of out-of-service and usable phone numbers, information on Internet connections in the area, information on congregate care and relocation facilities, information about donating and volunteering, and a message board.

One use of the Internet was to list the names of confirmed fatalities. It was useful for people overseas who could not call into Japan or who did not speak Japanese and therefore could not call emergency numbers (Williams, 1998). The Japanese Post, Telegraph, and Telephone Administration set up an automatic mailer to send the list via e-mail upon request (Newsbytes News Network, 1995).

The Internet proved useful when other communications methods failed. Telephone lines across the city were cut, and those that remained were overloaded. However, a local university still had an active Internet connection and network. A web page was set up, offering digital pictures of earthquake damage taken by a faculty member (Newsbytes News Network, 1995; Ivefors, 1997).

Loma Prieta Earthquake, California, 1989

The Internet also proved useful in the 1989 Loma Prieta earthquake. Many radio and television stations went off the air, some telephone services were lost, and many cables to distant radio transmitting antennas were destroyed. However, Internet communications remained largely unaffected by the earthquake (Wilson, 1991; Ivefors, 1997).

Ice Storm, United States and Canada, 1998

More recently, in January 1998, the Internet was used during another disaster - the ice storm in the northeastern United States and Canada. Although many phone and electrical lines went down, those that remained supported some Internet use. The New York State Emergency Management Office developed a web page presenting information such as lists of roads and colleges that were open, as well as warnings about the safe use of portable electric generators. In many cases emergency workers and residents struggled with the effects of the storm within their communities during the day, then accessed the web site in the evening to get the bigger picture of the emergency (New York State Emergency Management Office, 1998).

\section{Other Disasters}

The Internet has been used before, during, and after other disasters. For example, the Ruapehu volcanic eruptions in New Zealand in 1995-1996 were watched not only on television, but also on the Internet (Anderson, 1998). Some states have used web sites to post information such as descriptions of emergency exercises (Illinois Department of Nuclear Safety, 1999) and instructions about how to prepare for emergencies (Missouri State Emergency Management Agency, 1999). 


\section{ADVANTAGES OF THE INTERNET IN EMERGENCIES}

The Internet can provide interactivity, two-way communications, and multimedia information. One of its advantages is that a great deal of real-time information can be made available to a large audience. Access to these data can be either restricted or open to any Internet user.

The Internet can be used for one-way communication to individuals or groups, without permitting direct inquiries from those receiving the information. This feature could be advantageous for public information personnel. They could provide accurate information as it became available without having to respond immediately to a flood of inquiries from the media or the public.

However, people in disasters sometimes need a direct, interactive relationship with other individuals, either for exchanging information or simply for talking to someone. Though the Internet can be impersonal, this need can be somewhat addressed by providing points of contact with one-way data or by using on-line discussion groups.

\section{DISADVANTAGES OF THE INTERNET IN EMERGENCIES}

On the other hand, the Internet does have drawbacks. At present limited access is more of a problem world-wide than it is in the United States. A Nielsen Media Study estimated that more than one-third of adults in the United States use the Internet; this number is rising rapidly (Maggpie Communications, 1999). More than 100 million English-speaking people have Internet access, compared to about 80 million non-English-speaking people (Global Internet Statistics, 1999). To communicate on the Internet requires language literacy, computer literacy, and access to both a computer and the Internet.

Also, relevant portions of the Internet must be operational: both clients and servers need to be up and not overloaded. Internet service providers may themselves be affected by a disaster. Power outages can interfere with the use of computers; providing backup power can help to address this problem. All of the communications systems used during emergency responses can be vulnerable. Increased demand on the Internet by emergency organizations and the public is likely after an emergency. Thus, there may be network traffic overload. Restrictions on the use of the Internet by the public could be required.

In crisis situations, redundancy is a necessity that can be accomplished by having access to many different communication channels. Redundancy of web sites may also be needed in different regions so that demand can be rerouted.

Another drawback of the Internet can be its inherent freedom of speech. The quality of information on the Internet varies considerably. Bizarre ideas and false information have spread on the Internet in other contexts. Such misinformation can be expected to surface during emergencies. Some sort of rumor control operation will be needed to address such misinformation. 


\section{POTENTIAL USES OF THE INTERNET IN EMERGENCIES}

The Internet could support many command, control, and surveillance tasks in emergencies. Satellite communications, remote sensing images from space, and location data from global positioning system (GPS) satellites will become critical to the success of emergency organizations. These types of information can be integrated into the Internet. Together with geographic information systems, the GPS can be used to track the locations of resources and recovery operations. In emergencies where contaminants have been dispersed over a wide area, the gathering and analysis of samples can be crucial. The Internet can be used to communicate sample analysis results from multiple locations and integrate them into databases.

There are many other areas of potential Internet use. For example, listings of evacuees or relocated persons and their locations could be helpful in reuniting families. Shelter locations, route maps, and the status of special facilities could be updated dynamically. A web site with information on financial assistance and legal issues could provide instructions and forms for use by affected individuals and businesses. A web site could provide a centralized information locus for recovery efforts.

\section{POTENTIAL FOR USE OF HIGH-SPEED WIRELESS INTERNET IN DISASTERS}

Land-based telephone and cable lines can fail in disasters. Thus, independence from land lines is desirable for Internet use in emergencies. Radio-frequency wireless local area networks that use microwave technology are now available (Freed, 1998). Wireless communications could enhance the robustness of the system against disruption in disasters. Use of cellular telephones for connection to the Internet could offer independence from land lines. Global telephone systems that use satellites could become helpful in supporting wireless Internet use. Even now, hand-held satellite communicators send and receive short e-mail messages from any location on earth (Langenberg, 1998). For cities where large earthquakes are likely, backup radio or satellite links to the Internet should be considered if the Internet becomes part of the cities' disaster plans (Williams, 1998).

\section{SECURITY CONSIDERATIONS}

Although the Internet provides a new tool for rapidly disseminating information, this technology requires mechanisms to protect the integrity and sources of information.

Organizations may become dependent on the Internet and demand efficient communications even during emergencies. Security can also be a key concern, so as to protect web sites set up for emergency use from hackers and others who could alter information. Although technologies for protecting web sites are emerging, the availability of robust hacker tools has often maintained a lead over the technologies to protect sites.

The exchange of information between the public and the government, or between government agencies, requires protection methods similar to the encryption technologies used in electronic 
commerce. Encryption and certification technologies should be used to ensure that the information being exchanged is not altered, is not intercepted by unauthorized persons, and originates from the presumed source.

\section{SUMMARY AND CONCLUSIONS}

If a large disaster were to strike an area, the Internet could be immediately useful to organizations that have incorporated it into their emergency plans and procedures. It probably would have limited utility in getting immediate emergency information to the public. An exception could be natural disasters with long lead times, such as hurricanes. For members of the public who have access to the Internet, it could be useful for storm tracking and advance preparation. At present, most people can be expected to react to an emergency by turning to television or radio. As more members of the public gain access to the Internet, its viability for issuing immediate emergency information may increase.

However, after the onset of an emergency, the Internet may be expected to become much more useful for public communication. The Internet has considerable potential for providing answers that people need (information about the affected areas, communications status, identity of casualties, etc.) and should be able to relieve the load on other sources of emergency information. It should also be useful for appealing for specific equipment, personnel, help, and advice from people outside the affected area.

To summarize, the Internet has many potential uses during and after a disaster. Various concerns are associated with this use, such as limited access, security, and robustness. However, it is clear that we have not yet seen all of the potential uses of the Internet. We can look forward to new applications of what is already an extremely useful tool for emergency preparedness.

\section{ACKNOWLEDGMENTS}

Dr. Kenneth M. Bertram, Emergency Systems Group Manager, Argonne National Laboratory, provided helpful comments in developing this paper. This paper was prepared under U.S. Department of Energy contract W-31-109-ENG-38.

\section{REFERENCES}

Anderson, H. Living on the Edge. Science, 281:910-911, 1998.

Freed, L. Net Tools: Networks Made Easy. PC Magazine, 17(15):208-209, 1998.

Global Internet Statistics. Global Internet Statistics (by Language).

[http://www.euromktg.com/globstats], 1999, accessed March 30, 1999.

Illinois Department of Nuclear Safety. IDNS Home Page. [http://www.state.il.us/idns], 1999, accessed April 20, 1999. 
Ivefors, G.M. Emergency Information Management and Disaster Preparedness on the Internet. [http://www.hb.se/bhs/ith/gi.htm], 1997, accessed March 29, 1999.

Langenberg, M. Summon Help from Anywhere on Earth. Chicago Tribune, Sec. 4:2, Nov. 16, 1998.

Maggpie Communications, Inc. Our Digital Economy. [http://www.maggpie.com/theweb.html], 1999, accessed March 30, 1999.

Missouri State Emergency Management Agency. Radiological Emergency Planning (REP)

Program. [http://www.sema.state.mo.us/rpp.htm], 1999, accessed April 20, 1999.

Newsbytes News Network. Japan Quake Buzzes on the Internet.

[http://www.newsbytes.com/news/95/59913.html], 1995, accessed March 29, 1999.

New York State Emergency Management Office. Ice Storm ' 98 and State-Wide Flooding. [http://www.nysemo.state.ny.us/IceStorm98/icestorm98.htm], 1998, accessed March 29, 1999.

SONY Computer Science Laboratories. Kansai Area Earthquake Information. [http://www.csl.sony.co.jp/earthquake], 1995, accessed March 29, 1999.

Williams, M. Private communication. 1998.

Wilson, R.C. The Loma Prieta Quake: What One City Learned. International City Managers Association, Washington, DC, 1991.

\section{AUTHORS}

Dr. Donald E. Newsom is Program Manager for Emergency Preparedness Training with the Emergency Systems Group at Argonne National Laboratory. He holds a Ph.D. in Engineering (Large-Scale Systems) from Purdue University. His research includes systems analyses and computer simulations of natural and technological hazards, public warning, and response actions. He has developed and conducted over 100 workshops and courses in various aspects of emergency preparedness.

Dr. Caroline L. Herzenberg is a physicist and emergency engineer at Argonne National Laboratory. She has worked in various areas of technological emergency preparedness, including radiological emergency preparedness and the Chemical Stockpile Emergency Preparedness Program. She is a fellow of the American Physical Society, the American Association for the Advancement of Science, and the Association for Women in Science.

Dr. Craig E. Swietlik is Group Manager for Advanced Computer Applications in the Decision and Information Sciences Division at Argonne National Laboratory. He holds a Ph.D. in Computer 
Science/Applied Mathematics from Northwestern University. His research has focused on advanced information technology systems, including Internet applications, graphical user interfaces, and associated tools and technologies. 